\title{
4'C-Modified Nucleotides as Chemical Tools for Investigation and Modulation of DNA Polymerase Function
}

\author{
Daniel Summerer, Andreas Marx* \\ Kekulé-Institut für Organische Chemie und Biochemie, Universität Bonn, Gerhard-Domagk-Str. 1, 53121 Bonn, Germany \\ Fax +49(228)735388; E-mail: a.marx@uni-bonn.de
}

\begin{abstract}
DNA polymerases catalyze the entire biological DNA synthesis in DNA replication, repair and recombination. A DNA polymerase is presented with a pool of four structurally similar dNTPs from which it must select the sole correct substrate for incorporation into the growing DNA strand. The mechanisms how these remarkable enzymes achieve this tremendous task is a matter of current interest and intensive discussion. Valuable new insights into complex DNA polymerase selectivity mechanisms were gained through employment of $4^{\prime} \mathrm{C}$-alkylated nucleotide analogues in functional enzyme studies. First investigations indicate that the $4^{\prime} \mathrm{C}$-modified substrates are promising for the development of faithful methods for genome diagnostics.
\end{abstract}

$\begin{array}{ll}1 & \text { Introduction } \\ 2 & \text { DNA Polymerase Selectivity } \\ 3 & \text { Steric Probes for DNA Polymerases } \\ 4 & \text { Synthesis of 4'C-Alkylated Thymidines } \\ 5 & \text { Functional DNA Polymerase Studies } \\ 6 & \begin{array}{l}\text { DNA Polymerase Interactions with the Primer Template } \\ \text { Complex }\end{array} \\ 7 & \begin{array}{l}\text { Application of 4'C-Modified Primer Probes to Increase } \\ 8\end{array} \\ \text { Single Nucleotide Discrimination in PCR } \\ \text { Conclusions and Outlook }\end{array}$

Key words: DNA, nucleosides, nucleotides, oligonucleotides, DNA polymerase

\section{Introduction}

DNA polymerases catalyze the entire biological DNA synthesis in DNA replication, repair and recombination. ${ }^{1}$ Even in the simplest organisms these processes are conducted by complex machineries in which DNA polymerases are responsible for the transmission of the genetic information inscribed in the parental DNA sequence to the offspring. They catalyze proceeding template-directed phosphodiester bond formation between a $3^{\prime}-\mathrm{OH}$ of a primer strand to the $\alpha$-phosphate of an incoming $2^{\prime}$-deoxy nucleoside- $5^{\prime}$ - $O$-triphosphate (dNTP) leading to substitution of pyrophosphate (Figure 1). ${ }^{1,2}$

The above mentioned processes are of vital importance for any living species. For instance, given an average number of $10^{16}$ cell divisions in a human lifespan ${ }^{3}$ and an genome size of approximately $3 \cdot 10^{9}$, denotes that a human being is faced with about $3 \cdot 10^{27}$ nucleotide bond formations solely in replication processes. Obviously, the selec-

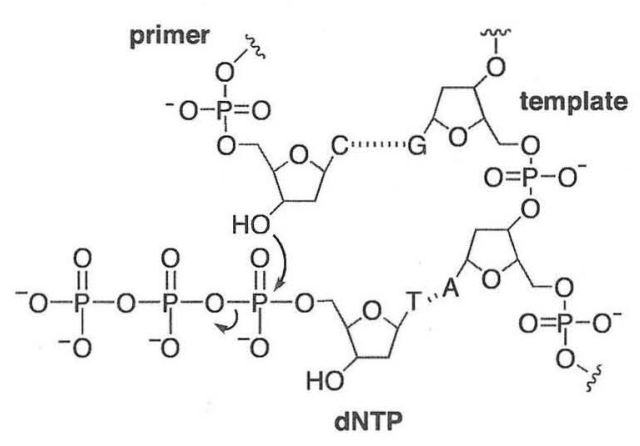

Figure 1

tivity of enzymatic DNA synthesis is essential for the maintenance of genome integrity. Thus, all DNA syntheses required for DNA repair, recombination and replication depend on the ability of DNA polymerases to recognize the template and correctly insert the complementary nucleotide. A DNA polymerase is presented with a pool of four structurally similar dNTPs from which it must select the sole correct (i.e., Watson-Crick base paired) substrate for incorporation into the growing DNA strand. The mechanisms how these remarkable enzymes achieve this tremendous task is a matter of interest and intensive discussion since the discovery of the first DNA polymerase, E. coli DNA polymerase I, by Kornberg about half a century ago. ${ }^{4}$

\section{DNA Polymerase Selectivity}

DNA polymerases that are involved in DNA replication processes exhibit low error rates of about only one error within $10^{5}$ to $10^{6}$ synthesized nucleotide linkages. ${ }^{4}$ What are the mechanistic properties that enable a DNA polymerase to catalyze nucleotide incorporation with a selectivity far greater than that dictated by the thermodynamic differences between base pairs in free solution?

On the first glance the formation of distinct hydrogen bonding patterns between the nucleobases of the coding template strand and the incoming nucleoside triphosphate might be responsible for the selective information transfer. Nevertheless, as been concluded by Goodman on the basis of thermal denaturation studies of matched and mismatched DNA complexes, these interactions alone are not sufficient to explain the extend of selectivity commonly 
observed for enzymatic DNA synthesis. ${ }^{4 h, 5}$ Thus, several additional factors have been discussed to be involved in correct nucleotide recognition. Among these factors are exclusion of water from the enzyme's active site, base stacking, solvation, minor groove scanning and steric constraints within the nucleotide binding pocket. ${ }^{4}$ The contribution of each of these features to net-DNA polymerase selectivity remains to be disentangle. Recently, in order to evaluate the participation of hydrogen bonding in DNA replication selectivity mechanisms, Kool described a seminal functional strategy based on chemically modified DNA polymerase substrates. ${ }^{4 a, d, 6-12}$ He developed nucleotide analogues in which the polar natural DNA nucleobases are replaced by non-polar aromatic molecules, which closely mimic the shape and size of the natural nucleobases but have at least significantly diminished ability to form stable hydrogen bonds. These non-polar nucleotide isosteres were applied as functional probes to elucidate the impact of hydrogen bonding on DNA polymerase selectivity. Kool and coworker found that the non-polar isosteres were processed with remarkable high selectivity and efficiency by several DNA polymerases. Based on these results it was concluded that hydrogen bonding is not required to achieve high incorporation efficiencies and that significant levels of selectivity can be achieved without hydrogen bonds. Close fitting of Watson-Crick geometry and satisfaction of specific minor groove interactions are among the most important factors in DNA replication. These results led to the advent of the steric model for DNA polymerase selectivity. In brief, DNA poly- merases form tight active sites composed out of the nucleotide binding pocket that are believed to be fixed in size and shape to accurately process canonical nucleobase pairs. Consensus nucleotides are processed efficiently while the non-consensus counterparts are excluded due to steric constraints imposed from the enzyme. ${ }^{4}$ This model was further supported by the finding that mutations that are believed to alter the geometry of the binding pocket effect the fidelity of the DNA polymerase. ${ }^{4 a, c}$ One of the most striking examples along this line is the Arg283Ala mutation in human DNA polymerase $\beta .{ }^{13} \mathrm{Arg} 283$ is part of the nucleotide binding pocket and its substitution with a sterically less demanding alanine moiety results in a marked decrease in fidelity. Similar results were obtained through mutation of $E$. coli DNA polymerase I and human immunodeficiency virus type-1 reverse transcriptase (HIV-1 RT) strongly suggesting the participation of steric constraints in DNA polymerase selectivity mechanisms.

\section{Steric Probes for DNA Polymerases}

Before we set on our investigations on DNA polymerases, no direct indication that steric constraints are indeed at play were reported. In our eyes this was mainly due to the lack of suitable functional means. Thus, we planned to develop nucleotide based probes for investigations of steric constraints imposed to the nucleotide substrates by DNA polymerases.

\section{Biographical Sketches}
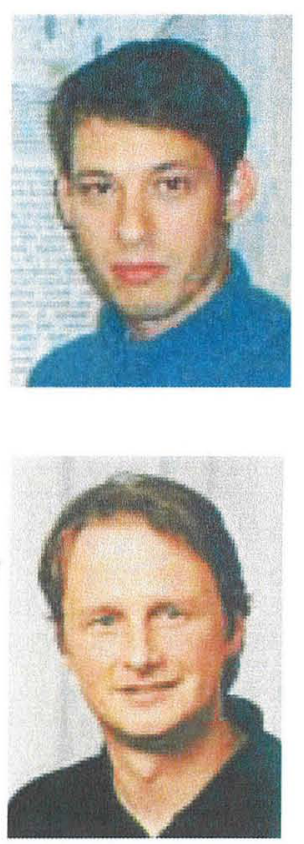

Daniel Summerer studied chemistry at the University of Bonn (Germany) and completed his Diploma with Andreas Marx on the syn- thesis of modified nucleosides and oligonucleotides. $\mathrm{He}$ is currently working on his doctorate on the development of assay formats for high-throughput screening of polymerase variants and is actively involved in combinatorial protein design.
Andreas Marx studied Chemistry in Freiburg (Germany), Sussex (UK), and Bochum (Germany). In 1997 he earned his doctorate at Basel University (Switzerland) with Prof. Bernd Giese. From 1997-1999 he was a EU/JSPS postdoctoral fellow with Prof. Hisashi Yamamoto at Nagoya Uni- versity (Japan). He began his independent career at the Kekulé-Institut für Organische Chemie und Biochemie at Bonn University (Germany) in fall 1999 and is currently heading an independent research group. In 2003 he completed his Habilitation and earned the Venia Legendi for Organic
Chemistry and Biochemistry. His awards include a stipend from the HellmutBredereck-Stiftung and a Junior Research Group by the Volkswagen Foundation. His research interest covers a wide area in the chemical biology of DNA replication processes. 
Our strategy is based on the employment of size augmented nucleotide analogues in functional DNA polymerase studies. We aimed at the design of nucleotide analogues with varying steric demand. The modifications should be chosen in a way that they interfere with as few as possible further alterations of the analogue's properties. Subsequently, after their synthesis the modified nucleotides are employed as substrates in functional DNA polymerase investigations. Insights into enzyme mechanism should be accessible through measurement of the efficacy of the analogues on DNA polymerase action and subsequent comparison to their natural counterparts.

The steric model of DNA polymerase selectivity is focused on nucleobase recognition processes and thus most functional studies comprise nucleobase analogues. ${ }^{4} \mathrm{Nev}$ ertheless, several crystal structures of DNA polymerases have been published and suggest that the sugar moiety of the incoming triphosphate is fully embedded in the nucleotide binding pocket (Figure 2) ${ }^{14}$ Furthermore, DNA polymerases have to distinguish faithfully between 2 'deoxyriboses present in dNTPs and ribose moieties present in NTPs. Thus, the enzyme sugar interactions are an integral part of the substrate recognition process. ${ }^{15} \mathrm{Lit}-$ tle is known about the impact of DNA polymerase interactions with the 2'-deoxyribose moiety and their participations in processes which contribute to overall enzyme fidelity. Obviously, there is no direct selectivity readout of the enzyme through the sugar moiety since all four nucleotides have the same sugar. Nevertheless, noncanonical nucleobase interactions might govern altered sugar conformations that are likely to be edited by the DNA polymerase within the tight nucleotide binding pocket. Thus, the sugar residues might be indirectly involved in selectivity mechanisms.

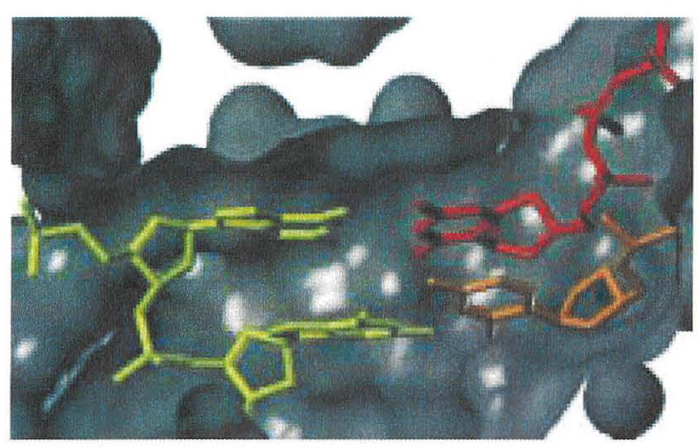

Figure 2 View in the nucleotide binding pocket of Thermus aquaticus (Taq) DNA polymerase. Structure is based on PDB entry $3 \mathrm{KTQ} .{ }^{14 \mathrm{~h}}$ Selected template residues in yellow, primer 3 '-terminal nucleotide residue in orange and incoming dNTP in red. Solvent accessibility surface (probe radius $1.4 \AA$ ) is depicted in gray.

To sense steric constraints in DNA polymerases within the nucleotide binding pocket acting on the sugar moiety of an incoming nucleoside triphosphate we developed a functional strategy based on $4^{\prime} \mathrm{C}$-alkylated thymidines. The steric probes $\mathbf{T}^{\mathbf{R}} \mathbf{T P}$ were designed by substituting the $4^{\prime} \mathrm{C}$-hydrogen atom of thymidine- $5^{\prime}$ - $O$-triphosphate (TTP) with alkyl groups that continually increase in their steric bulk (Figure 3). ${ }^{16}$ Alkyl substituents at the $4{ }^{\prime} \mathrm{C}$ position were chosen since we wanted to keep interference of the modification with hydrogen bonding, nucleobase pairing and stacking at minimum.

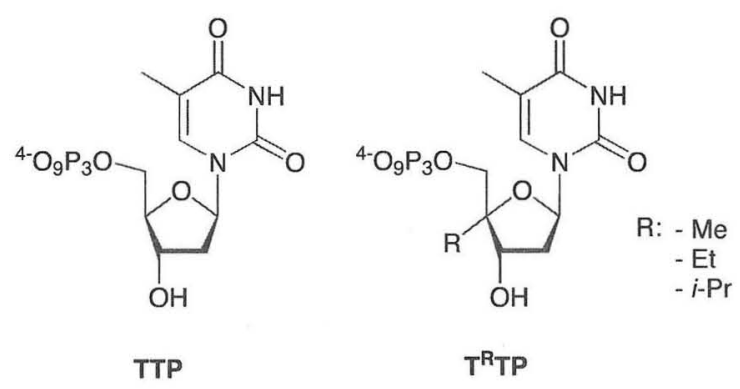

Figure 3 Steric probes for DNA polymerase mechanisms: $4^{\prime} \mathrm{C}$-Alkylated thymidine triphosphates.

\section{Synthesis of $4^{\prime} \mathrm{C}$-Alkylated Thymidines}

Obviously, the envisaged biochemical investigations were contingent on a suitable access to the probes. Thus, we first had to develop a route that allows the synthesis of the modified thymidine analogues in significant amounts. Our synthesis started with the known alcohol $\mathbf{1}$, which is easily accessible in high quantities as described recently (Scheme 1). ${ }^{17,18}$ Alcohol $\mathbf{1}$ was converted into iodide 2 by treatment with $\mathrm{I}_{2}, \mathrm{Ph}_{3} \mathrm{P}$ and imidazole. Hydrogenation with $\mathrm{Pd} / \mathrm{C}$ in the presence of $\mathrm{Et}_{3} \mathrm{~N}$ and subsequent cleavage of the silyl ethers with tetrabutylammonium fluoride (TBAF) gave $4^{\prime} \mathrm{C}$-methyl thymidine $3 \mathrm{a}$ in good yield. $4^{\prime} \mathrm{C}$ Ethylated thymidine $\mathbf{3 b}$ was synthesized in high yield from easily available aldehyde 4 , following sequential Wittig reaction, desilylation and subsequent reduction of the aliphatic double bond. Finally the synthesis of thymidine analogue $3 \mathbf{c}$, bearing a bulky $i$-propyl group in $\alpha$-position to the $4^{\prime} \mathrm{C}$-quarternary carbon center, was accomplished from known ketone 7 through a Wittig reaction and subsequent desilylation and hydrogenation of the aliphatic double bond. Next, nucleosides $3 \mathbf{a}-\mathbf{c}$ were converted into the desired triphosphates $\mathbf{T}^{\mathrm{R}} \mathbf{T P}$.

Although the depicted route seems to be laborious on the first glance it allows the synthesis of the desired nucleotides $\mathbf{T}^{\mathrm{R}} \mathbf{T P}$ in amounts needed for the numerous planed biochemical investigations on DNA polymerases.

\section{$5 \quad$ Functional DNA Polymerase Studies}

If the steric model of DNA replication selectivity holds true and enzyme interactions with the sugar moiety are involved in selectivity processes, we expected the modifications to decrease the tolerance for geometrically altered 
A
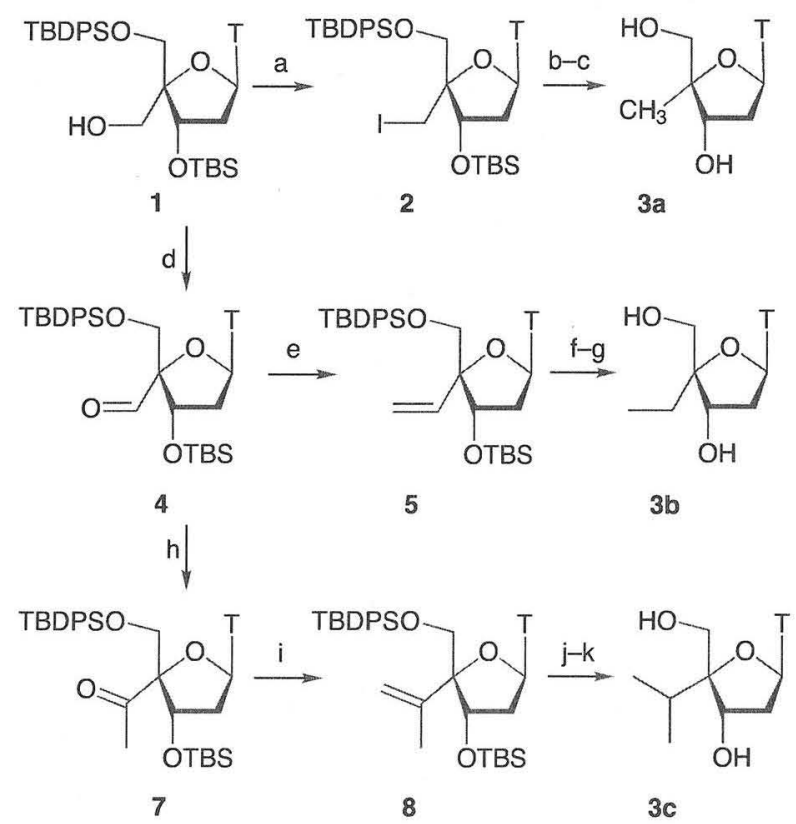

B

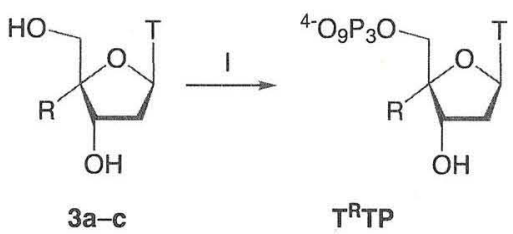

Scheme 1 a) $\mathrm{Ph}_{3} \mathrm{P}, \mathrm{I}_{2}$, imidazole, $\mathrm{C}_{6} \mathrm{H}_{6}$; b) $\mathrm{Pd} / \mathrm{C}, \mathrm{H}_{2}$, EtOH, EtOAc, $\mathrm{NEt}_{3}$; c) TBAF, THF; d) $\left(\mathrm{Cl}_{3} \mathrm{CCO}\right)_{2} \mathrm{O}$, DMSO, $\mathrm{Et}_{3} \mathrm{~N}, \mathrm{CH}_{2} \mathrm{Cl}_{2}$; e) $\mathrm{CH}_{3} \mathrm{PPh}_{3} \mathrm{Br}, n$-BuLi, THF; f) TBAF, THF; g) $\mathrm{Pd} / \mathrm{C}, \mathrm{H}_{2}, \mathrm{CH}_{3} \mathrm{OH}$; h) oxidation $;{ }^{18} \mathrm{~h}$ ) alkylation and oxidation; ${ }^{18}$ i) $\mathrm{CH}_{3} \mathrm{PPh}_{3} \mathrm{Br}, t$-BuOK, THF; j) TBAF, THF; k) Pd/C, $\mathrm{H}_{2}, \mathrm{CH}_{3} \mathrm{OH}$; l) $\mathrm{POCl}_{3}, \mathrm{MeO}_{3} \mathrm{PO}, 1,8-$ bis(dimethylamino)-naphthalene, followed by bis(tri- $n$-butylammonium) pyrophosphate, DMF, $n-\mathrm{Bu}_{3} \mathrm{~N}$.

conformations of nascent nucleotide pairs resulting in an increase in nucleotide insertion selectivity. Indeed, we found that increasing the bulk of nucleoside triphosphates through employment of the probes $\mathbf{T}^{\mathbf{M e}} \mathbf{T P}$ and $\mathbf{T}^{\mathrm{E} t} \mathbf{T P}$ led to a marked increase in nucleotide insertion selectivity catalyzed by an $3^{\prime} \rightarrow 5^{\prime}$-exonuclease deficient mutant of the Klenow fragment $\left(\mathrm{KF}^{-}\right)$of $E$. coli DNA polymerase I. ${ }^{16}$ Based on steady-state kinetic analysis the enzyme is capable to insert $\mathbf{T}^{\mathrm{Me}} \mathbf{T P}$ and $\mathbf{T}^{\mathrm{E}} \mathbf{T P}$ with high efficiency opposite a canonical template base. On the other hand, misinsertion opposite non-canonical bases is approximately 100 -fold less efficient compared to the natural substrate $\mathbf{T}^{\mathrm{H}} \mathbf{T P}$. Thus, these results support the model that steric constraints are at least one crucial determinant of DNA polymerase selectivity.

As described above, DNA polymerase selectivity is believed to be achieved mainly by editing nucleotide shape and size within a tight nucleotide binding pocket. Yet, DNA polymerase selectivity often varies significantly depending on the DNA polymerase. ${ }^{4,19}$ The origin of this varying error propensity is elusive. It is assumed that DNA polymerases form nucleotide binding pockets that differ in properties like shape and tightness. ${ }^{4 a}$ Thus, high fidelity DNA polymerases are believed to form more rigid binding pockets tolerating less geometric deviation while low fidelity enzymes exhibit more flexibility leading to decreased fidelity. However, this concept of active site tightness remains to be tested experimentally.

In order to gain insight into differential DNA polymerases properties like selectivity of DNA synthesis we compared the efficacy of the steric probes $\mathrm{T}^{\mathrm{R}} \mathbf{T P}$ on $\mathrm{KF}^{-}$with that on human immunodeficiency virus type-1 reverse transcriptase (HIV-1 RT), an enzyme known for its error propensity. ${ }^{20,21}$ Initially, we reckoned that an error-prone DNA polymerase (like HIV-1 RT) would process the bulkier thymidines more efficiently than the more selective enzyme $\mathrm{KF}^{-}$. However, while investigating HIV-1 $\mathrm{RT}$ in 'correct' insertion of the different $\mathrm{T}^{\mathrm{R}} \mathrm{TP}$, we found little difference between HIV-1 RT and $\mathrm{KF}^{-} .{ }^{16,20}$ Analyzing misinsertion, the two enzymes behave differently. While $4 C^{\prime}$-methylation has little effect on the selectivity of HIV-1 RT, significant effects are observed for $\mathrm{KF}^{-}{ }^{16,20}$ Thus, based on the above mentioned concept of active site tightness our results suggest that both enzymes most significantly differ when promoting misinsertion rather than insertion opposite canonical template bases. This might be the result of differential active site conformations causing different steric constraints while promoting 'incorrect' in comparison to 'correct' nucleotide insertion.

In certain cases amino acid substitutions on the active site are known to effect the selectivity of DNA polymerases. ${ }^{4}$ One of such mutations in HIV-1 RT is M184V. Through M184V mutation an $\alpha$-methyl side chain present in valine is introduced that is believed to contact the sugar ring of the incoming triphosphate and thus, reduce the available space on the active site to be filled by the incoming dNTP. ${ }^{14 \mathrm{j}, 22}$ Consistent with the steric model, this mutation has been shown to result in increased nucleotide insertion selectivity. Employing the steric probe $\mathbf{T}^{\mathrm{R}} \mathbf{T P}$ this sizeaugmentation was monitored by the increased bulk resulting in significantly lower misinsertion efficiency by the M184V mutant compared to the natural substrate. ${ }^{20}$

In summary, these studies provide first experimental evidence that variations of steric constraints within the nucleotide binding pocket of at least two DNA polymerases cause differences in nucleotide incorporation selectivity.

DNA synthesis by DNA polymerases follows an ordered reaction pathway comprising conformational changes after binding of the incoming dNTP substrate. ${ }^{23}$ To study these processes rapid kinetic means like quench-flow have to be employed. Thus, pre-steady kinetic measurements of HIV-1 RT and the M184V mutant were conducted employing the steric probes $\mathbf{T}^{\mathbf{R}} \mathbf{T P}{ }^{24} \mathrm{We}$ found that, depending on the severity of the structural distortion, initial binding of the nucleoside and induced fit are involved in discrimination against a canonical base pairing. The obtained data further highlight the importance of tight fitting 
A

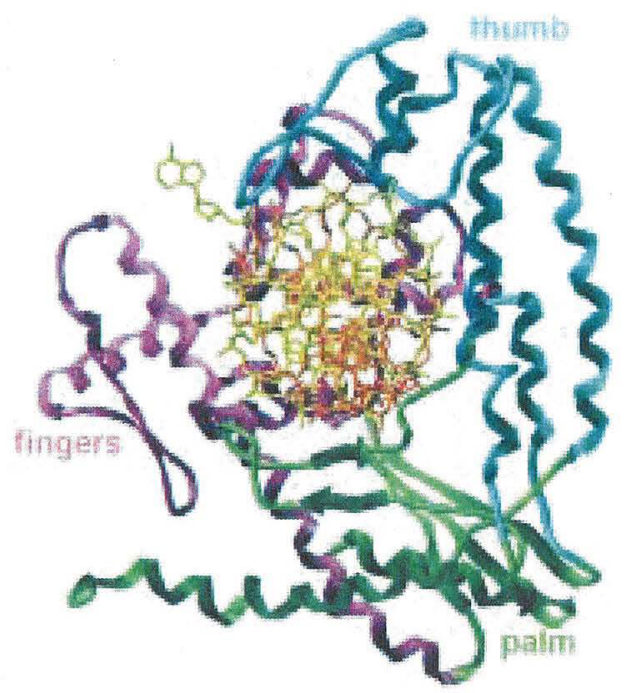

B

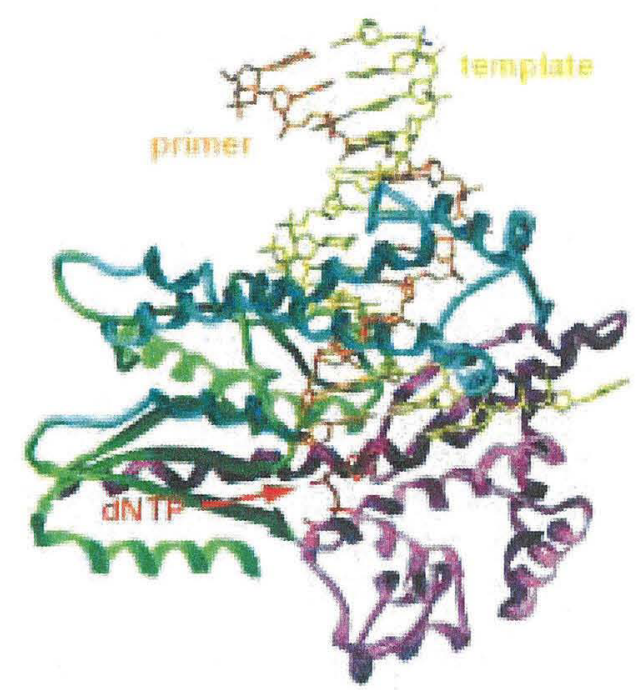

Figure 4 Structure of Thermus aquaticus (Taq) DNA polymerase bound to the DNA primer-template complex and dNTP. ${ }^{14 h}$ Structure is based on PDB entry 3KTQ. The respective sub-domains are colored as indicated in the figure. A: view perpendicular to the helix axis; B: top view showing the active site and primer template binding cleft.

of the nucleotide substrate within the DNA polymerase active site and further corroborate the notion that the sugar moiety is also an important element of the substrate recognition process.

\section{DNA Polymerase Interactions with the Primer Template Complex}

Recently determined crystal structures of several DNA polymerases in complex with their DNA and dNTP substrates have contributed significantly to our understanding of structure and substrate recognition by these complex enzymes. ${ }^{14}$ Most DNA polymerases with known structures exhibit the formation of a large cleft in which the primer template complex is embedded. In analogy of this conformation with a half open right hand the enzyme domains are termed thumb, palm, and fingers (Figure 4). The palm domain harbors the catalytic center comprising the essential carboxylates involved in the phosphoryl transfer reaction. The high degree of conservation of this domain throughout distinct DNA polymerase families form eukaryotic, prokaryotic, and viral DNA polymerases is striking. In contrast, the finger and thumb domains that undergo extensive contacts with the primer template complex and the incoming dNTPs differ significantly among DNA polymerases.

The structural investigations suggest that DNA polymerases make complex interactions with the primer-template and nucleotide substrates during catalysis of DNA polymerization. Enzyme contacts with the primer template complex are manifold and reaching up to several nucleotide pairs beyond the catalytic center. ${ }^{14}$ These interactions primarily occur through the minor groove of the DNA duplex with the sugar-phosphodiester backbone. To gain insights into the participation of these complex enzyme-DNA contacts in DNA polymerase function, we intended to develop new steric probes to investigate interactions acting on the DNA primer template duplex through incorporation of $4^{\prime} \mathrm{C}$-alkylated thymidines into the respective positions of the DNA substrates. ${ }^{25}$

To monitor steric constraints acting on the minor groove of the DNA duplex the above depicted 4'C-alkyl modifications incorporated into the respective positions in the primer template duplex should be ideally suited as steric probes.

In order to incorporate $4^{\prime} \mathrm{C}$-alkylated thymidines $\mathbf{3 a - c}$ into oligonucleotides, 3a-c were converted into 2-cyanoethylphosphoramidite building blocks through conversion into the respective 4,4'-dimethoxytrityl ethers $9 \mathbf{a}-\mathbf{c}$ and subsequent phosphitylation to form $\mathbf{1 0 a - c}$ (Scheme 2). ${ }^{17}$

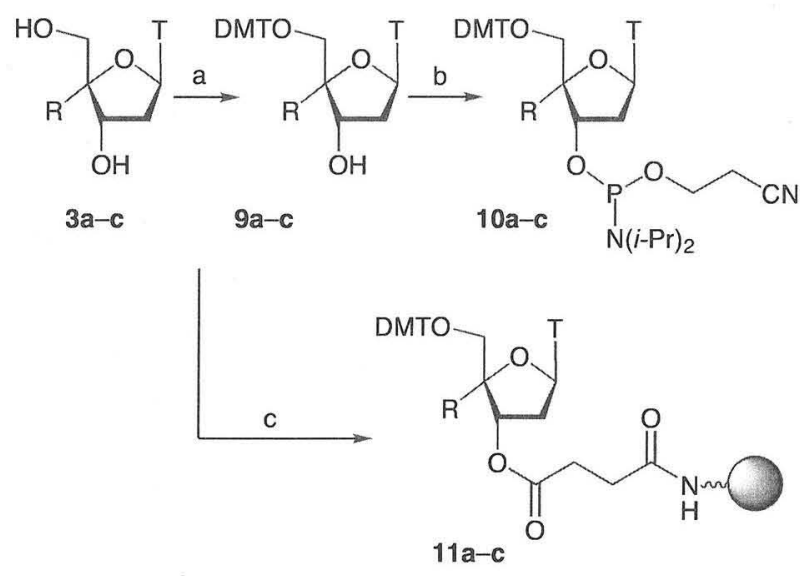

Scheme 2 a) DMTCl, pyridine, DMAP, b) (i$\left.\mathrm{Pr}_{2} \mathrm{~N}\right)\left(\mathrm{NCCH}_{2} \mathrm{CH}_{2} \mathrm{O}\right) \mathrm{PCl}, i-\mathrm{Pr}_{2} \mathrm{~N}$ Et, $\mathrm{CH}_{2} \mathrm{Cl}_{2} ;$ c) succinylated long chain alkyl amine modified controlled pore glass (LCAA-CPG), DMAP, EDC, $\mathrm{NEt}_{3}$, pyridine; then 4-nitrophenol, then piperidine, then acetic anhydride, DMAP, pyridine. 

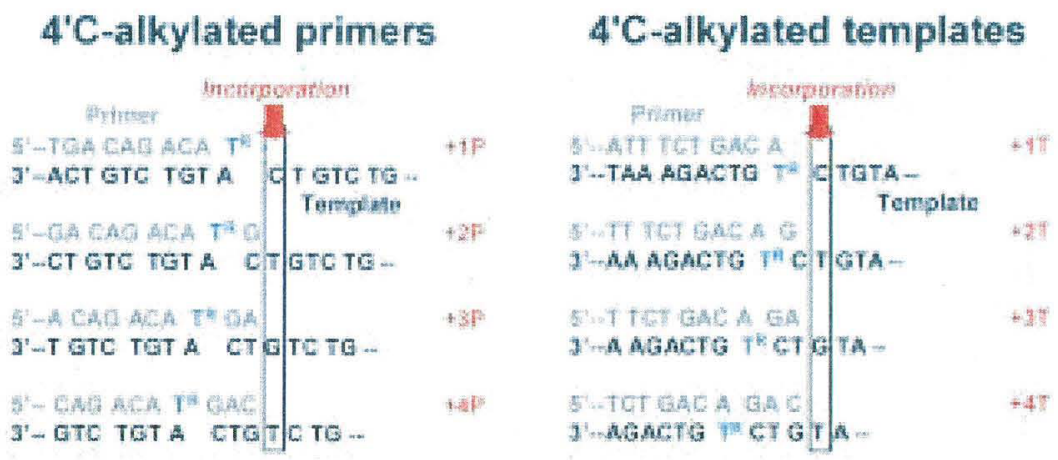

Scheme 3 Substrates synthesized to probe DNA polymerase interactions with the primer or template strand, respectively. $\mathrm{T}^{\mathrm{R}}$ : thymidines bearing $4^{\prime} \mathrm{C}-\mathrm{H}$, methyl, ethyl, or $i$-propyl.

For the synthesis of oligonucleotides bearing the $4^{\prime} \mathrm{C}$ modified thymidines at the $3^{\prime}$-end of the DNA strands we coupled 4,4'-dimethoxytrityl ethers $\mathbf{9 a}-\mathbf{c}$ to succinylated long chain alkyl amine controlled pore glass (LCAACPG) support applying standard procedures. We were able to synthesize $4^{\prime} \mathrm{C}$-modified oligonucleotides by automated DNA synthesis applying commercially available 2cyanoethylphosphoramidites and the modified building blocks with only slight changes of the standard protocols leading to the site-specifically $4^{\prime} \mathrm{C}$-modified oligonucleotides in comparable yields to those obtained for unmodified oligonucleotides.

First we investigated the effect of $4^{\prime} \mathrm{C}$-alkylation on duplex stability and conformation. ${ }^{17,26}$ Thus, we performed thermal denaturation studies and measured $T_{m}$-values. In cases where only one modified residue per duplex was introduced, we found little effects of $4^{\prime} \mathrm{C}$-alkylation on duplex stability compared to the unmodified oligonucleotides. To explore whether $4^{\prime} \mathrm{C}$-alkylation has significant impact on overall DNA helix conformation, we examined the circular dichroism (CD) for all native and modified oligonucleotides. Here again, we found that complementary duplexes are formed, which exhibit little deviations of overall helix conformation compared to the unmodified counterparts.

Next, we focused our attention to the development of the steric probes for investigation of interaction between a DNA polymerase and the primer template duplex as mentioned above. ${ }^{25}$ To address interactions of the enzyme at several nucleotide positions within the DNA duplex we synthesized numerous oligonucleotides bearing site-specifically introduced $4^{\prime} \mathrm{C}$-alkyl groups as steric probes (Scheme 3). In functional DNA polymerase studies, we expected that DNA modifications primarily cause altered kinetic properties of the enzyme through perturbation of native enzyme-substrate interactions at those positions where relevant DNA-enzyme contacts exist. To monitor steric constraints acting on the minor groove of DNA we applied $4^{\prime} \mathrm{C}$-alkyl modifications as steric probes which continually increase in steric bulk (see Scheme 3; $\mathrm{T}^{\mathrm{R}}$ : thymidines bearing $4^{\prime} \mathrm{C}-\mathrm{H}$, methyl, ethyl, or $i$-propyl).
We investigated a $3^{\prime} \rightarrow 5^{\prime}$-exonuclease deficient mutant of the Klenow fragment of $E$. coli DNA polymerase I $\left(\mathrm{KF}^{-}\right)$. The results from the quantitative steady-state analysis showed that substitution of the $4^{\prime} \mathrm{C}$-hydrogen with a methyl group at $+1 \mathrm{P}$ cause a 2000 -fold reduction of nucleotide insertion efficiency (see Figure 5A).

As the methyl modification moves further beyond the catalytic center no such pronounced effects on the efficiency were measured anymore. Bulkier ethyl and $i$-propyl groups interfere with DNA synthesis primarily at positions $+1 \mathrm{P}$ and $+2 \mathrm{P}$ while at $+3 \mathrm{P}$ and $+4 \mathrm{P}$ no significant effects were detected. The profoundly less efficient DNA synthesis observed at the two first nucleotides beyond the nucleotide binding pocket can be rationalized by most functionally important KF interactions with the sugar moieties at $+1 \mathrm{P}$ and $+2 \mathrm{P}^{25}$

Next, we investigated KF minor groove contacts with the template strand (Figure 5B). In contrast to the results described above the most prominent influence on DNA polymerase function was observed at position $+4 \mathrm{~T}$ and $+2 \mathrm{~T}$ distal from the active site where nucleotide incorporation is performed. Quantitative studies indicate that the effects on enzyme efficiency are more than 200-fold at position $+4 \mathrm{~T}^{25}$

Subsequently, we investigated whether $4^{\prime} \mathrm{C}$-modified primer strands have any effects on the base substitution fidelity of DNA synthesis. We speculated that addition of steric strain through $4^{\prime} \mathrm{C}$-alkyl modifications would cause less flexibility of the $3^{\prime}$-primer end and a decreased tolerance of geometrically altered nascent mispairs. Indeed, we were able to show that through application of $4^{\prime} \mathrm{C}$ modified primer probes the amount of misinsertion products were diminished indicating a higher selectivity of the DNA polymerase reaction governed by $4^{\prime} \mathrm{C}$-modifications. ${ }^{25}$

In conclusion, these investigations show that through application of $4^{\prime} \mathrm{C}$-alkylated probes valuable insights into DNA polymerase function can be gained. 

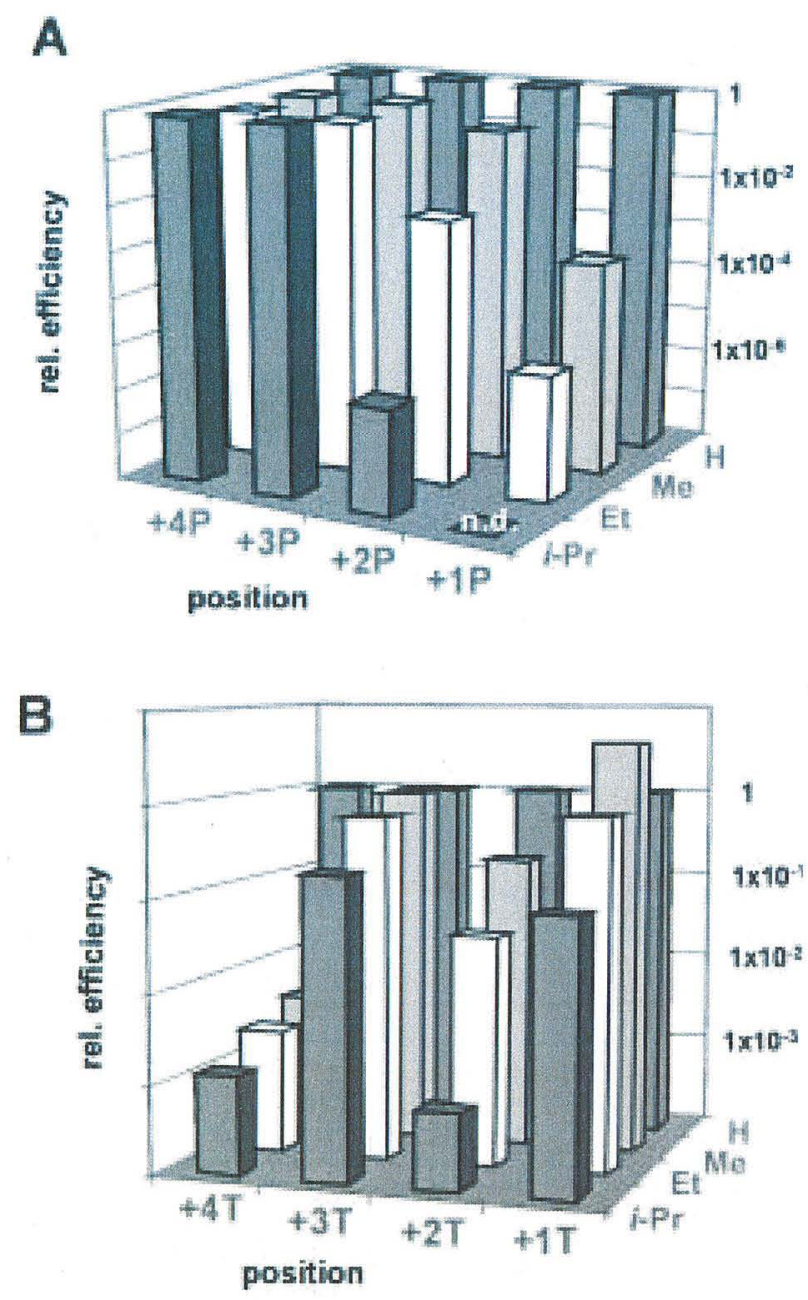

Figure 5 Graphical depiction of the results obtained in studies of $\mathrm{KF}^{-}$using the steric probes shown in Scheme 3. A: results obtained through use of $4^{\prime} \mathrm{C}$-modified primer strands; $\mathrm{B}$ : results obtained through use of 4'C-modified template strands. rel. efficiency: $\left(\mathrm{V}_{\max } / \mathrm{K}_{\mathrm{M}}\right)_{\mathrm{T}}{ }^{\mathrm{R}}$ $\left(\mathrm{V}_{\max } / \mathrm{K}_{\mathrm{M}}\right)_{\mathrm{T}}{ }^{\mathrm{H}}$ measured under steady-state conditions. n.d.: not detected.

\section{Application of 4'C-Modified Primer Probes to Increase Single Nucleotide Discrimination in PCR}

Recent advances in pharmacogenomics call for methods that allow rapid diagnosis of genome variations like single nucleotide polymorphisms (SNPs). ${ }^{27-30}$ Many methods for the detection of nucleotide variations in genes have been described to date. ${ }^{31-34}$ Nevertheless, each method exhibits advantages and disadvantages, and thus, no methodology has prevailed so far. Most known methods are applied after amplification of the target genome sequence through the polymerase chain reaction (PCR). Thus, after isolation of the genetic material, the sequence of interest has to be amplified by PCR prior to the analytical step determining a nucleotide variation. Obviously, reliable methods that allow direct detection of nucleotide varia- tions through PCR would supercede those that apply after PCR. Allele-specific amplification has been described to report nucleotide variations through either the presence or absence of a DNA product obtained through PCR amplification based on the formation of matched or mismatched primer template complexes through allele-specific primer probes. ${ }^{35-38}$ From matched 3'-primer termini PCR amplification by a DNA polymerase proceeds, while a mismatch should obviate amplification. Nevertheless, there have been many reports indicating low selectivity of this approach necessitating further tedious time- and cost-intensive optimizations. ${ }^{39-42}$ Thus, any means that increase the single-nucleotide discrimination of PCR should have significant impact on the reliability and robustness of this promising and simple approach.

Encouraged by our finding that the selectivity of the DNA polymerase reaction can occasionally be increased by $4^{\prime} \mathrm{C}$-modified substrates, we thought about the employment of $4^{\prime} \mathrm{C}$-alkylated probes as primers in PCR. We speculated that the flexibility at the 3 '-primer end can be decreased as well through these modifications resulting in lower DNA polymerase propensity for extension of geometrically altered mismatched primer template complexes. Such a system could in turn be the basis for the development of a novel highly allele-specific PCR approach. Indeed, we were able to show that this concept is applicable and found significant increase of the specificity of PCR by using chemically modified primer probes. ${ }^{43}$ We found that in all investigated single mismatches, significantly higher amplification selectivity can be observed by use of $4^{\prime} \mathrm{C}$-vinylated primer probes and Vent exo ${ }^{-}$DNA polymerase compared to cases were unmodified primers were used. Nevertheless, the exact knowledge about the processes in this system that govern for the increased single-nucleotide discrimination remain mainly elusive and are the subject for future investigations.

\section{Conclusions and Outlook}

Our studies show that valuable new insights into complex DNA polymerase mechanisms, that are otherwise difficult to access, can be gained through application of $4^{\prime} \mathrm{C}$-alkylated nucleotide substrates. In future we will investigate the origins of the often striking variations of selectivity and substrate tolerance among several prominent highfidelity and error-prone DNA polymerases. First investigations indicate that the $4^{\prime} \mathrm{C}$-modified substrates are promising for the development of faithful methods for genome diagnostics. Nevertheless, further improvements along this line are strongly needed. Progress is envisaged employing chemical and genetical means.

\section{Acknowledgment}

Our work is supported by the Volkswagen-Stiftung, Deutsche Forschungsgemeinschaft, Roche Diagnostics, Fonds der Chemischen Industrie, and Dr. Otto Röhm Gedächtnisstiftung, that is gratefully acknowledged. We thank Professor Dr. M. Famulok for his support during the time at Bonn University. 


\section{References}

(1) Kornberg, A.; Baker, T. A. DNA Replication, 2d ed.; W. H. Freeman and Company: New York, 1991.

(2) (a) Joyce, C. M.; Steitz, T. A. Annu. Rev. Biochem. 1994, 63, 777. (b) Steitz, T. A.; Smerdon, S. J.; Jäger, J.; Joyce, C. M. Science (Washignton, DC, U.S.A.) 1994, 266, 2022.

(3) Alberts, B.; Bray, D.; Lewis, J.; Raff, M.; Roberts, K.; Watson, J. D. In Molekularbiologie der Zelle, 3rd Ed.; VCH: Weinheim, 1995, 1495.

(4) Reviews: (a) Kool, E. T. Annu. Rev. Biochem. 2002, 71, 191. (b) Patel, P. H.; Loeb, L. A. Nat. Struct. Biol. 2001, 8, 656. (c) Kunkel, T. A.; Bebenek, K. Annu. Rev. Biochem. 2000, 69, 497. (d) Kool, E. T.; Morales, J. C.; Guckian, K. M. Angew. Chem. Int. Ed. 2000, 39, 991. (e) Kunkel, T. A.; Wilson, S. H. Nat. Struct. Biol. 1998, 5, 95.

(f) Diederichsen, U. Angew. Chem. Int. Ed. 1998, 37, 1655; Angew. Chem. 1998, 110, 1745. (g) Goodman, M. F. Proc. Natl. Acad. Sci. U.S.A. 1997, 94, 10493. (h) Echols, H.; Goodman, M. F. Annu. Rev. Biochem. 1991, 60, 477.

(5) Petruska, J.; Goodman, M. F.; Boosalis, M. S.; Sowers, L. C.; Cheong, C.; Tinoco, J. r. I. Proc. Natl. Acad. Sci. U.S.A. $1988,85,6252$.

(6) Ren, R. X.-F.; Chaudhuri, N. C.; Paris, P. L.; Rumney, I. V. S.; Kool, E. T. J. Am. Chem. Soc. 1996, 118, 7671.

(7) Moran, S.; Ren, R. X.-F.; Rumney, I. V. S.; Kool, E. T. J. Am. Chem. Soc. 1997, 119, 2056.

(8) Moran, S.; Ren, R. X.-F.; Kool, E. T. Proc. Natl. Acad. Sci. U.S.A. 1997, 94, 10506.

(9) Morales, J. C.; Kool, E. T. Nat. Struct. Biol. 1998, 5, 950.

(10) Matray, T. J.; Kool, E. T. Nature 1999, 399, 704.

(11) Morales, J. C.; Kool, E. T. J. Am. Chem. Soc. 2000, 121, 2323.

(12) Morales, J. C.; Kool, E. T. J. Am. Chem. Soc. 2000, 122, 1001.

(13) Beard, W. A.; Osheroff, W. P.; Prasad, R.; Sawaya, M. R.; Jaju, M.; Wood,'T. G.; Kraut, J.; Kunkel, T. A.; Wilson, S. H. J. Biol. Chem. 1996, 271, 12141.

(14) (a) Johnson, S. J.; Taylor, J. S.; Beese, L. S. Proc. Natl. Acad. Sci. U.S.A. 2003, 96, 12224. (b) Silvian, L. F.; Toth, E. A.; Pham, P.; Goodman, M. F.; Ellenberger, T. Nat. Struct. Biol. 2001, 8, 984. (c) Zhou, B.-L.; Pata, J. D.; Steitz, T. A. Mol. Cell 2001, 8, 427. (d) Trincao, J.; Johnson, R. E.; Escalante, C. R.; Prakash, S.; Prakash, L.; Aggarwal, A. K. Mol. Cell 2001, 8, 417. (e) Boudsocq, H.; Ling, F.; Woodgate, R.; Yang, W. Cell 2001, 107, 91. (f) Franklin, M. C.; Wang, J.; Steitz, T. A. Cell 2001, 98, 413. (g) Doublié, S.; Tabor, S.; Long, A. M.; Richardson, C. C.; Ellenberger, T. Nature (London, U.K.) 1998, 391, 251. (h) Korolev, Y.; Li, S.; Waksman, G. EMBO J. 1998, 17, 7514. (i) Kiefer, J. R.; Mao, C.; Braman, J. C.; Beese, L. S. Nature (London, U.K.) 1998, 391, 304. (j) Huang, H. F.; Chopra, R.; Verdine, G. L.; Harrison, S. C. Science 1998, $282,1669$.

(15) (a) Minnick, D. T.; Liu, L. X.; Grindley, N. D. F.; Kunkel, T. A.; Joyce, C. M. Proc. Natl. Acad. Sci. U.S.A. 2002, 99, 1194. (b) Joyce, C. M. Proc. Natl. Acad. Sci. U.S.A. 1997, 94, 1619.

(16) Summerer, D.; Marx, A. Angew. Chem. Int. Ed. 2001, 40, 3693.

(17) Detmer, I.; Summerer, D.; Marx, A. Eur. J. Org. Chem. 2003, 1837.

(18) Marx, A.; Erdmann, P.; Senn, M.; Körner, S.; Jungo, T.; Petretta, M.; Imwinkelried, P.; Dussy, A.; Kulicke, K. J.; Macko, L.; Zehnder, M.; Giese, B. Helv. Chim. Acta 1996, 79, 1980.

(19) Reviews: (a) Goodman, M. F. Annu. Rev. Biochem. 2002, 71, 17. (b) Hübscher, U.; Maga, G.; Spadari, S. Annu. Rev.
Biochem. 2002, 71, 133. (c) Marx, A.; Summerer, D. ChemBioChem 2002, 3, 405. (d) Friedberg, E. C.; Fischhaber, P. L.; Kisker, C. Cell 2001, 107, 9. (e) Livneh, Z. J. Biol. Chem. 2001, 276, 25639. (f) Goodman, M. F.; Tippin, B. Nat. Rev. Mol. Cell Biol. 2000, 1, 101. (g) Hübscher, U.; Nasheuer, H. P.; Syvaoja, J. E. Trends Biochem. Sci. 2000, 25, 143. (h) Friedberg, E. C.; Feaver, W. J.; Gerlach, V. L. Proc. Natl. Acad. Sci. U.S.A. 2000, 97 , 5681. (i) Friedberg, E. C.; Gerlach, V. L. Cell 1999, 98, 413 (j) Johnson, R. E.; Washington, M. T.; Prakash, S.; Prakash, L. Proc. Natl. Acad. Sci. U.S.A. 1999, 100, 3895.

(20) Strerath, M.; Cramer, J.; Restle, T.; Marx, A. J. Am. Chem. Soc. 2002, 124, 11230.

(21) (a) Preston, B. D.; Poisez, B. J.; Loeb, L. A. Science 1988 242, 1168. (b) Roberts, J. D.; Bebenek, K.; Kunkel, T. A. Science 1988, 242, 1171. (c) Bebenek, K.; Abbotts, J.; Roberts, J. D.; Wilson, S. H.; Kunkel, T. A. J. Biol. Chem. 1989, 264, 16948. (d) Bebenek, K.; Abbotts, J.; Wilson, S. H.; Kunkel, T. A. J. Biol. Chem. 1993, 268, 10324.

(22) (a) Sarafianos, S. G.; Das, K.; Clark, A. D. Jr.; Ding, J.; Boyer, P. L.; Hughes, S. H.; Arnold, E. Proc. Natl. Acad. Sci. U.S.A. 1999, 96, 10027. (b) Gao, H.-Q.; Boyer, P. L.; Sarafianos, S. G.; Arnold, E.; Hughes, S. H. J. Mol. Biol. 2000, 300, 403.

(23) (a) Kati, W. M.; Johnson, K. A.; Jerva, L. F.; Anderson, K. S. J. Biol. Chem. 1992, 267, 25988. (b) Johnson, K. A. Annu. Rev. Biochem. 1993, 62, 685. (c) Wöhrl, B. M.; Krebs, R.; Goody, R. S.; Restle, T. J. Mol. Biol. 1999, 292, 333.

(24) Cramer, J.; Strerath, M.; Marx, A.; Restle, T. J. Biol. Chem. 2002, 277, 43593.

(25) (a) Summerer, D.; Marx, A. J. Am. Chem. Soc. 2002, 124, 910. (b) Strerath, M.; Summerer, D.; Marx, A. ChemBioChem 2002, 3, 578.

(26) Detmer, I.; Summerer, D.; Marx, A. Chem. Commun. 2002, 2314.

(27) Licinio, L.; Wong, M. Pharmacogenomics; Wiley-VCH: Weinheim, 2002.

(28) McCarthy, J. J.; Hilfiker, R. Nat. Biotechnol. 2000, 18, 505.

(29) Evans, W. E.; Relling, M. V. Science 1999, 286, 487.

(30) Relling, M. V.; Dervieux, T. Nat. Rev. Cancer 2001, 1, 99.

(31) Kwok, P. Y. Annu. Rev. Gen. Hum. Genet. 2001, 2, 235.

(32) Kirk, B. W.; Feinsod, M.; Favis, R.; Kliman, R. M.; Barany, F. Nucleic Acids Res. 2002, 30, 3295.

(33) Syvänen, A. C. Nat. Rev. Genet. 2001, 2, 930.

(34) Twyman, R. M.; Primrose, S. B. Pharmacogenomics 2003 , $4,67$.

(35) Newton, C. R.; Graham, A.; Heptinstall, L. E.; Powell, S. J. Summers, C.; Kalsheker, N.; Smith, J. C.; Markham, A. F. Nucleic Acids Res. 1989, 17, 2503.

(36) Gibbs, R. A.; Nguyen, P. N.; Caskey, C. T. Nucleic Acids Res. 1989, 17, 2437.

(37) Germer, S.; Holland, M. J.; Higuchi, R. Genome Res. 2000, 10, 258.

(38) Wu, D. Y.; Ugozzoli, L.; Pal, B. K.; Wallace, R. B. Proc. Natl. Acad. Sci. U. S. A. 1989, 86, 2757.

(39) Shively, L.; Chang, L.; LeBon, J. M.; Liu, Q.; Riggs, A. D.; Singer-Sam, J. Biotechniques 2003, 34, 498.

(40) Guo, Z.; Liu, Q. H.; Smith, L. M. Nat. Biotechnol. 1997, 15, 331.

(41) Ishikawa, Y.; Tokunaga, K.; Kashiwase, K.; Akaza, T.; Tadokoro, K.; Juji, T. Hum. Immunol. 1995, 42, 315.

(42) Wilhelm, J.; Reuter, H.; Tews, B.; Pingoud, A.; Hahn, M. Biol. Chem. 2002, 383, 1423.

(43) Strerath, M.; Marx, A. Angew. Chem. Int. Ed. 2002, 41, 4766. 